\title{
La Revista Católica de Cuestiones Sociales, 1895-1916: La Recepción de la Rerum Novarum
}

\section{The Revista Católica de Cuestiones Sociales, 1895-1916: The Reception of Rerum Novarum}

RECIBIDO: 16 DE JUNIO DE 2021/ ACEPTADO: 21 DE ENERO DE 2022

\author{
TOMÁS MARTÍNEZ VARA \\ Universidad Complutense \\ ORCID: 0000-0002-9971-0867
}

Resumen: El nacimiento de la Revista Católica de Cuestiones Sociales (1895-1930) coincidió con el verdadero "despegue" del catolicismo social español, que tuvo una notable relevancia a finales del siglo XIX y comienzos del XX. Fue una de las revistas más importantes y duraderas de las que difundieron en España la Doctrina Social de la Iglesia, y en ella participaría gran parte de la intelectualidad católica de la época. El objetivo de este trabajo es analizar cómo se recibió en la revista, durante sus primeros años (18951916), la gran encíclica social de León XIII, la Rerum Novarum (1891), con alguna alusión puntual a la Graves de Communi (1901). Aunque con matices derivados de la convivencia de visiones "integristas" con otras más "avanzadas", en esta publicación periódica se hizo en general una lectura bastante tradicional y conservadora de ambos textos.

Palabras clave: Catolicismo Social, España, $R e^{-}$ vista Católica de Cuestiones Sociales, Rerum Novarum, Cuestión Social

\author{
JOSÉ LUIS RAMOS GOROSTIZA \\ Universidad Complutense \\ ORCID: oooo-0002-1187-1464 \\ ramos@ccee.ucm.es
}

Abstract: The birth of the Revista Católica de Cuestiones Sociales (1895-1930) coincided with the true "take-off" of Spanish Social Catholicism, which had a notable relevance at the end of the 19th century and the beginning of the 2oth. It was one of the most important and long-lasting journals of those that spread the Social Doctrine of the Church in Spain, and a large part of the Catholic intelligentsia of the time would participate in it. The objective of this work is to analyze how the great social encyclical of Leo XIII, the Rerum Novarum (1891), were received in the journal during its early years (1895-1916), with some occasional allusion to the Graves de Communi (1901). Although with nuances derived from the coexistence of "fundamentalist" visions with other more "advanced" ones, in this periodical publication a fairly traditional and conservative reading of both texts was generally made.

Keywords: Social Catholicism, Spain, Revista Católica de Cuestiones Sociales, Rerum Novarum, Social Question 


\section{INTRODUCCIÓN}

La Revista Católica de Cuestiones Sociales (RCCS) comenzó su andadura en Madrid en 1895, y se mantuvo hasta diciembre 1930, a sólo cuatro meses de la proclamación de la II República y de que Pío XI publicase la Quadragesimo Аnпо. Su nacimiento coincidió con el verdadero "despegue" del catolicismo social español.

Fue una de las revistas más importantes y duraderas de las que en España difundieron la Doctrina Social de la Iglesia, en la que participaría gran parte de la intelectualidad católica de finales del siglo XIX y comienzos del XX ${ }^{1}$. Asimismo, fue quizá el principal y "más cualificado" órgano de expresión del catolicismo social español, que a su vez tuvo una notable relevancia durante el primer tercio del siglo $\mathrm{XX}^{2}$. Sin embargo, hasta la fecha no se ha dedicado a la revista un estudio específico, que es precisamente lo que se pretende hacer en este trabajo, si bien referido sólo a sus inicios, entre 1895 y 1916. El objetivo es analizar cómo se recibió la gran encíclica social de León XIII, la doctrinal Rerum Novarum $(R N)$ de 1891, haciendo también alguna alusión puntual a la Graves de Communi (1901) sobre la democracia cristiana.

Como es sabido, León XIII puso en el primer texto los cimientos de la Doctrina Social de la Iglesia, planteando a nivel teórico una tercera vía -hasta cierto punto equidistante- entre el capitalismo ultraliberal, cuyos excesos condenó, y el socialismo y el anarquismo, a los que reprobó sin paliativos. En la segunda encíclica, limitó la democracia cristiana a la acción social a favor del pueblo, desestimando cualquier tipo de interpretación liberal-democrática como la que defendían en Europa algunos propagandistas del catolicismo social. El rechazo de los fundamentos filosófico-liberales no impidió al pragmático pontífice aceptar, como "mal menor", que los católicos participasen en las reglas de juego político de los estados liberales, especialmente cuando se tratara de asuntos sociales ${ }^{3}$. Por otro lado, este Papa también asumió en la práctica una cierta compatibilidad entre ciencia y verdad cristiana, y entre libertades modernas y catolicismo. Otra cosa diferente fue la ambivalente postura que en España adoptaron al respecto las distintas "familias" católicas, que osciló entre la estima, la indiferencia y el rechazo. Tal disparidad de criterios quedaría también patente en la RCCS.

\footnotetext{
1 Andrés-Gallego, J. (1984), p. 363.

2 Montero, F. (1983) p. 285. Hubo también otras revistas relevantes, como La Paz Social de Severino Aznar.

3 Montero, F. (2007), pp. 102-105.
} 
A diferencia de Bélgica, Francia y Alemania, en España la nueva conciencia del problema social, entendida como algo más que un mero problema de beneficencia, había sido muy residual antes de la publicación de la $R N^{4}$. En este sentido, esta encíclica no ratificó un movimiento previo, sino que más bien despertó e impulsó una conciencia nueva, receptiva a las exigencias de la justicia y el deber moral de la caridad, en un país que llevaba acumulado un gran retraso económico y social respecto a otros de su entorno, pero que en absoluto se encontraba estancado. De hecho, desde mediados del siglo XIX venía experimentando un crecimiento económico apreciable.

El fin declarado de la RCCS era contribuir al proceso recristianizador de una sociedad cada vez más secularizada, tomando como base la $R N$ : "Ella será la fuente a donde irán a beber las aguas de la verdad nuestros colaboradores" . Este objetivo había sido fijado por León XIII con motivo de la primera peregrinación obrera española al Vaticano en $1895^{6}$. En concreto, este Papa había animado al movimiento católico español a establecer asociaciones para la difusión de la nueva cultura social de la Iglesia, y también a potenciar la prensa profesional como herramienta de defensa y "reconquista". Con tales fines, a su regreso de Roma, miembros de la élite económica y política patrocinaron la "Asociación General para el Estudio y Defensa de los Intereses de las Clases Trabajadoras". Su gran promotor, que también había liderado la citada peregrinación, fue Claudio López-Bru (1853-1925), segundo marqués de Comillas. Monárquico y pragmático, supo mantenerse en una línea alejada de las facciones menos moderadas del catolicismo ${ }^{7}$, como el carlismo y su ala integrista, aunque les profesara simpatía y respeto y apoyase abiertamente a alguno de sus miembros, como José Ignacio Suárez de Urbina (1856-1928), figura clave de la RCCS.

Este abogado sevillano encarnó mejor que nadie el prototipo del laico entregado a la labor de propaganda católica ${ }^{8}$. Ortodoxo e intransigente en materia religiosa y miembro de Comunión Tradicionalista, creó en 1895 el "Patronato Social de Buenas Lecturas". Desde dicho Patronato, y gracias al apoyo de la aristocracia católica más tradicional -con Comillas a la cabeza-, puso en marcha diversas iniciativas editoriales. Entre ellas destacaron la exitosa "Biblioteca Patria de Obras Premiadas" (1903-1931), para el fomento de "bue-

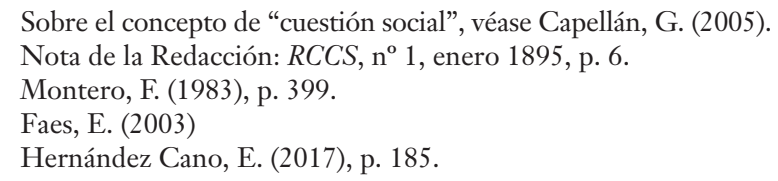


nas lecturas" que sirvieran al comportamiento cristiano, y la RCCS. Esta última acabó siendo la "piedra angular" del Patronato y el gran logro de Urbina, que sería su director hasta su fallecimiento en 1928. Aunque no existen datos sobre su tirada, el hecho de que cada número pasase de tener inicialmente unas quince páginas, a sumar finalmente alrededor de cien, parece indicar que disfrutó de bastante aceptación.

En connivencia con el marqués de Comillas, Urbina pretendía que en las páginas de la RCCS se trataran las cuestiones sociales de actualidad, al objeto de que se aplicara la Doctrina Social sin moverse un ápice de la "más pura ortodoxia" " Desde el primer momento, Urbina lograría involucrar en el sostenimiento de la publicación a un nutrido grupo de prelados y aristócratas encabezados por el marqués de Comillas, en su mayoría prohombres ligados a la alta política: por ejemplo, los marqueses de Cerralbo (Enrique de Aguilera y Gamboa), de Vadillo (Francisco de Castejón y Elío) y de Lema (Salvador Bermúdez de Castro); el duque de Sotomayor (Carlos Martínez de Irujo); el barón de Satrústegui (Enrique de Satrústegui Berrié); o el conde de Castrillo y Orgaz (Esteban Crespi de Valldaura y Fortuny). Conforme pasaron los años, nuevos "patronos" de heterogénea identidad (clérigos, abogados, aristócratas, industriales, intelectuales, funcionarios) se irían añadiendo a esta lista, de modo que al final el conjunto de "protectores" de la revista -seglares y eclesiásticos- acabaría haciéndose extensísimo.

Tanto a la hora de seleccionar colaboradores, como de confeccionar los dos principales órganos de la RCCS -la Comisión Central de Propaganda y el Consejo de Redacción-, Urbina mostró una encomiable capacidad para "armonizar tendencias" entre las diferentes "familias" del conservadurismo católico. Ello resultó especialmente importante en los primeros tiempos de la revista, cuando las furibundas diatribas políticas entre "carlistas, integristas y mestizos" estaban a la orden del día, insultándose y desautorizándose continuamente desde sus respectivas publicaciones ${ }^{10}$.

Respecto a la citada Comisión, sabemos que sus integrantes no variaron entre 1896 y 1912: Manuel Mariátegui y Vinyals (conde de San Bernardo, que

9 Así lo afirmó Manuel Sánchez Cuesta, (1028) RCCS, nº408, p. 361.

10 "Mestizo" fue el vocablo despectivo que carlistas e integristas (los "íntegros") usaban para referirse a los accidentalistas o posibilistas del "mal menor", especialmente a los pidalianos, aludiendo al carácter impuro o no integralmente católico de su opción. Alejandro Pidal, líder de la Unión Católica, intentó sin éxito una alianza estable con el carlismo, lo que le llevó -según González Cuevas, P.C. (2001), p. 116 - a integrarse en el partido liberal-conservador de Cánovas. Aunque crítico con la modernidad, consideraba imposible -como Balmes- el retorno a la época premoderna. 
murió en 1905 sin ser reemplazado); los marqueses de Lema y Vadillo; Francisco Lastres (jurista experto en delincuencia juvenil); y Joaquín Sánchez de Toca. Todos ellos fueron políticos conservadores muy significados que desempeñaron altos cargos. Lamentablemente, ignoramos cuál fue su peso real en la toma de decisiones dentro de la RCCS.

En cuanto al Consejo de Redacción, tanto el número como la identidad de los consejeros varió bastante, al menos entre los años 1895-1908 (último del que se dieron datos). Eran en su mayoría de elevada formación intelectual, con muchos académicos y profesores universitarios. Por ejemplo, en el primer Consejo de 1895 (11 miembros) había carlistas prominentes (como el catedrático de Derecho Político de Salamanca Enrique Gil Robles, el integrista y catedrático de Economía de Santiago Alfredo Brañas, o el político y orador Juan Vázquez de Mella), junto a destacados pidalianos (como el catedrático de Metafísica de la Central Juan Manuel Ortí y Lara, su discípulo, el político y ensayista Damián Isern, el político y jurista Sánchez de Toca, y el catedrático de Derecho Natural de la Central, Francisco de Castejón, marqués de Vadillo). A ellos se añadían el moderado Juan Mañé y Flaquer (catedrático de Latín en Barcelona), Eduardo Sanz y Escartín (jurista y académico), Delfín Donadiu (catedrático de Hebreo en la Universidad de Barcelona), y Antonio Pérez Córdoba (profesor de Apologética en el Seminario Conciliar de Sevilla y colaborador de los Círculos del influyente Zeferino González) ${ }^{11}$.

El autor de la reveladora declaración programática de la revista, titulada "Nuestros propósitos", fue Vázquez de Mella, ideólogo del tradicionalismo carlista ${ }^{12}$. Afirmó que, más allá de la arena política, en el terreno social-propio de la RCCS - la cooperación entre las distintas "familias" católicas conservadoras (tradicionalistas carlistas, integristas y posibilistas) resultaba necesaria. Y pidió que se abordaran con sentido práctico todas las "soluciones" que planteaba la Doctrina Social de la Iglesia en la estela de la $R N$ : por ejemplo, encontrar formas de participación de los trabajadores en los beneficios empresariales, recuperar lo mejor de la tradición de los gremios ("expurgándo-

11 En un próximo trabajo, si encontramos documentación, tenemos intención de ocuparnos de otras variables, tales como el número de suscriptores y su composición social, las formas de financiación, la publicidad incluida, etc.

12 RCCS, $\mathrm{n}^{\circ} 1,1895$, pp. 2-5. En 1897, Vázquez de Mella intervino en la redacción del "Acta de Loredán”, el programa que levantó la estructura ideológica del nuevo carlismo y donde se aceptó el catolicismo social como solución de la llamada cuestión social (Orella, J.L., 2012, pp. 24-25). El Acta citaba expresamente la $R N$, señalaba la armonía social laboral como el gran objetivo a alcanzar (patronos y obreros unidos por relaciones morales y jurídicas anteriores a la ley de la oferta y la demanda), y proponía la vía corporativa para alcanzarla. 
los de sus inconvenientes"), fomentar el cooperativismo (de consumo, crédito y producción), o apoyar iniciativas relativas a bancos populares, tribunales de arbitraje y vivienda obrera. Todo ello bajo un llamamiento constante al principio de la caridad, la moral cristiana y cierto paternalismo propio de la "aristocracia de sangre”. El fin último era evitar el conflicto de clases, logrando el equilibrio social e impidiendo el abuso de los más poderosos, que debían demostrar "generosidad y altura de miras". En suma, recomendaba que la publicación siguiera un enfoque pragmático, adaptado a las cambiantes exigencias de los tiempos y alejado de abstracciones vacías.

En la RCCS se publicaron artículos doctrinales, informaciones sobre el movimiento social, textos legales y clásicos, y selecciones bibliográficas. Entre los colaboradores más habituales destacó el catedrático de Economía Armando Castroviejo, que realizó numerosas contribuciones y recensiones, dentro de la influyente sección "Revista de Revistas y Bibliográfica" que él mismo dirigió en dos etapas: entre enero de 1899 y marzo de 1903, y entre noviembre de 1910 y diciembre de $1930^{13}$. En el periodo intermedio, dicha sección fue controlada por los integristas T. Jiménez de Tejera y Manuel Sánchez Asensio (Kall D'Eron), discípulo y amigo de Enrique Gil Robles, quien a su vez firmó para la revista numerosos textos de temática muy variada. Sánchez Asensio dirigió asimismo, entre noviembre de 1910 y enero de 1913, la sección fija "Crónica Social Española”, que pasó luego a ser controlada -hasta el final- por su hijo, el también integrista Manuel Sánchez Cuesta (Mirabal). Probablemente, fue también Sánchez Asensio quien introdujo como colaborador en la RCCS al prolífico León Leal Ramos, que hasta 1912 -en que abandonó Madrid- dejó decenas de artículos sobre temas diversos (crédito agrícola, usura, contratos de trabajo, educación, etc. $)^{14}$. Otros dos importantes colaboradores habituales, entre 1913 y 1930, fueron Juan Hinojosa Ferrer, hijo del ilustre historiador Eduardo Hinojosa y Naveros y uno de los primeros especialistas en Derecho Laboral ${ }^{15}$, y José Polo Benito, deán de la catedral de Toledo ${ }^{16}$.

13 Esporádicamente compartió la sección con el abogado M. Ruiz de Tudanca.

14 Montáñez, R. (2000).

15 Hinojosa viajó a Francia en 1907, pensionado para estudiar el movimiento social francés. Fue miembro del cuerpo técnico del Instituto de Reformas Sociales, y Juez de Primera Instancia en Zaragoza desde 1915.

16 Polo Benito fue un gran activista social vinculado a la previsión social en su región adoptiva, siendo el alma de la Caja de Ahorros de Plasencia. Colaboró también con Leal Ramos en el nacimiento de la Caja de Previsión Extremeña (Flores de Manzano, F., 2012). En 1923 se trasladó a Toledo convirtiéndose en deán de la catedral. Polo Benito se lamentaba del escaso nivel cultural de la prensa católica. 
Y entre 1908 y 1930 destacó María de Echarri, principal voz feminista del catolicismo social conservador. Juan Hinojosa no tuvo asignada una sección específica, sino que, como otros columnistas coetáneos (F. Melgar, T. Jiménez de Tejeda, J. Rubio Coloma, M. Ruiz de Tudanca, B. López Centeno o el mencionado J. Polo Benito), escribió sobre infinidad de asuntos. Sí la tuvo en cambio, desde 1913, María de Echarri: se titulaba "Crónica del movimiento femenino católico", y versaba sobre el papel de la mujer en el ideario social católico ${ }^{17}$.

Finalmente, hay que resaltar una idea clave: durante el período de vida de la RCCS, 1895-1930, el pensamiento conservador fue todo menos homogéneo. Por eso, en la revista existió una amplia pluralidad de posicionamientos y matices ideológicos entre sus redactores. Dicha pluralidad fue a su vez, en unos casos, producto de una lenta, sinuosa y progresiva renovación intelectual, y -en otros- fruto de la simple adaptación a la realidad socioeconómica cambiante. Pero tampoco faltaron viajes de ida y vuelta, como el experimentado - por ejemplo- por el aludido Gil Robles (del carlismo al integrismo, $\mathrm{y}$ de nuevo del integrismo al carlismo ${ }^{18}$. La línea que marcaba las diferencias era a menudo difusa, aunque el punto principal de desunión entre los católicos giraba en torno a la teoría del "mal menor", inaceptable a todas luces para carlistas e integristas. Sin embargo, existían también importantes nexos entre todos ellos, como el énfasis en la cuestión social, la exaltación de la dignidad de la persona, y la defensa racional y moral del derecho de propiedad privada, la cooperación, o la protección de la familia como célula básica de la sociedad. Quizá por ello, en general -y pese a los distintos matices- los redactores de la $R C C S$ hicieron una lectura bastante tradicional y conservadora de las dos grandes encíclicas de León XIII.

\section{PRIMEROS TEXTOS}

La RCCS empezó a publicarse unos meses después de la ya citada peregrinación a Roma y de la celebración del IV Congreso Católico Nacional de

17 RCCS, nº161, 1908, p. 295.

18 Parece oportuno recordar, con Hibbs-Lissorgues, S. (1995, p. 16), que "en la prensa de la época términos como neocatólico, integro, católico rancio, mestizos y transaccionistas [la cursiva es suya] tenían muchas veces una carga subjetiva y despreciativa y resultaban difíciles de interpretar, ya que no designaban siempre una realidad sociopolítica precisa". 
Tarragona. Lo hizo con la reproducción íntegra -por entregas- de la $R N^{19}$, advirtiendo a los lectores que todos los escritos doctrinales que en ella aparecieran tenían que inspirarse necesariamente en dicha encíclica ${ }^{20}$. Un supuesto que explica por qué, en los enfoques de colaboradores y redactores, al margen de su inclinación política, primaron las coincidencias sobre las discrepancias, que fueron casi siempre de matiz.

Le siguió la divulgación de la carta apostólica Permoti Nos, que León XIII había remitido un mes antes al episcopado de Bélgica a propósito de la gran controversia que el tema de la "cuestión social" había suscitado entre los católicos belgas ${ }^{21}$. Probablemente la Dirección tomó la decisión de difundirla pensando que el contenido de la carta era en buena medida extrapolable al caso español, en donde también proliferaban las discrepancias entre los católicos. Sea como fuere, Permoti Nos era un documento conciso pero denso, donde el pontífice, sobre la base de la $R N$, reflexionaba acerca del origen, significado y relevancia de la llamada "cuestión social", al tiempo que trazaba determinadas directrices de acción. Entendía León XIII que la compleja problemática social debía contemplarse desde varias dimensiones: materiales, tradicionales (costumbres), legales (derechos y deberes) y, sobre todo, religiosas (pues la religión ayudaba a resolver los conflictos y regulaba las relaciones con sentido moral). Recomendaba a los católicos belgas trabajar con ahínco en todo "lo conducente al bien común, dejando de lado a sus particulares opiniones"; procurar que la autoridad y la libertad individual se vieran "cristianamente conciliadas", absteniéndose de cualquier "acto sedicioso que alter[ase] la tranquilidad del reino"; y ofrecer su apoyo tanto a la mejora de las instituciones civiles y las escuelas, como a la prosperidad del comercio. Todo ello debía ir unido a un patronazgo responsable que contribuyese a mejorar la situación y las oportunidades de la clase obrera, mientras que a los obreros les incumbía la obligación de ser "respetuosos y fieles para con sus patronos". La verdadera causa del conflicto social -concluía el pontífice- no residía en las desigualdades propias de la naturaleza humana, sino en el abuso que se hacía de ellas, que era el que se debía erradicar para conciliar las diferencias de clase.

En paralelo con los dos citados documentos pontificios, la Revista publicó en sus primeros meses algunos textos reseñables de miembros del Consejo de Redacción, a veces muy breves, que hacían referencia a aspectos con-

19 RCCS, ${ }^{\circ} 1-5$.

20 RCCS, $\mathrm{n}^{\circ} 1,1895$, p. 6 , nota 1.

21 RCCS, no8, 1895, pp. 124-126. 
cretos de la Doctrina Social de la Iglesia. Cronológicamente, los dos primeros fueron: uno -muy tradicional- del marqués de Vadillo, sobre sobre la función de la Iglesia como redentora de la "cuestión social" a través de la caridad ${ }^{22}, \mathrm{y}$ otro del canónigo Antonio Pérez de Córdoba, sobre la propiedad, glosando la $R N^{23}$. Era este un derecho que el pontífice consideraba "clave de bóveda" de la estabilidad social, requisito fundamental para el progreso de las naciones, y condición indispensable para el ejercicio de la libertad humana y la salvaguardia del orden público. Fundado en la naturaleza física y moral del hombre, era anterior a todo pacto social y no derivaba su eficacia de las leyes civiles que lo reconocían y defendían. Pero, según Pérez de Córdoba, aceptar el principio de propiedad privada como legítimo y natural frente a los ataques del socialismo no implicaba solidarizarse con los abusos que de él pudieran derivarse, ni considerar que su distribución fuera entonces, para el caso de la tierra y los instrumentos del trabajo, "la mejor y más equitativa" posible. Llegado el caso, el Estado podía incluso -con la prudencia de la que hablaba el pontífice- determinar las condiciones que regulaban el ejercicio de este derecho, y armonizar la utilización de las cosas por sus legítimos dueños para provecho de la colectividad.

Les siguieron los textos del industrial lanero y político catalán J. Sallarés y Pla, sobre "derroteros necesarios" ${ }^{24}$, y del arquitecto madrileño E.M. Repullés y Vargas, sobre "barrios obreros" 25 . Para Sallarés, predominaba entonces el materialismo ateo al margen de toda moral, algo que ni las mejoras materiales en la posición del proletariado, ni el ejercicio de la caridad por las clases pudientes (creando escuelas, asilos, sanatorios, etc.), habían conseguido cam$\operatorname{biar}^{26}$. El único medio de lograrlo era la formación cristiana de los trabajadores. Sin ella y sin el espíritu cristiano de la caridad, no podrían funcionar el arbitraje, los gremios o el crédito agrícola, ni tampoco podría resolverse el conflicto social. Por su parte, Repullés, que seguía de cerca los debates europeos, no consideraba oportuno construir barrios "económicos" diferenciados en las ciudades, porque ello implicaba separar a la clase obrera del resto de la sociedad. Pensaba que, para ejercer la caridad, se precisaba la proximidad del obrero a fin de poder ayudarle, protegerle y remediar sus necesidades. Del

22 RCCS, nº2, 1895, pp. 23-25.

23 RCCS, $\mathrm{n}^{\circ} 2,1895$, pp. $17-19 ; \mathrm{n}^{\circ} 3,1895$, pp. 33-36; nº, 1895, pp. 84-86.

24 RCCS, nº, 1895, pp. 80-83.

25 RCCS, nº 4,1895 , pp. 49-42.

26 Presidente del Gremio de Fabricantes de Sabadell (1885-1892) y del Fomento del Trabajo Nacional (1897-1898). 
mismo modo, para recuperar la moral se requería también la proximidad, la convivencia y el ejemplo, lo que favorecía asimismo el orden social. Tales eran las grandes ventajas de los sistemas mixtos de estratificación social.

Igualmente, es reseñable el prólogo que el catedrático de Economía Política Antonio Pou y Ordinas dedicó a la novela Les suites d'une grève (1892), del estadístico y economista liberal franco-alemán Maurice Block, que había sido traducida por el propio Pou y con cuyo contenido se sentía "completamente identificado". La Redacción justificó la reproducción de un fragmento del texto de Pou en la RCCS aduciendo que ambos, prólogo y novela, contenían todo lo que convenía saber "al obrero, al capital y a la sociedad" para armonizarse y erradicar el conflicto social, actuando conforme a "las leyes naturales de la economía del trabajo" y "la dignidad humana". La cuestión social sólo se resolvería, según Pou, con un triple compromiso: si los obreros aceptaban el carácter natural de las leyes económicas, reconocían como necesarias las funciones de los empresarios, y evitaban la huelga (que a todos perjudicaba); si los empresarios, por su parte, asumían con decisión sus deberes de dirección y patronazgo, ejercitando la caridad cristiana como estabilizadora del orden social; $\mathrm{y}$-finalmente- si el Estado se limitaba a promulgar leyes que favoreciesen la concordia en el mundo del trabajo con medidas justas y prudentes, que procurasen el bien común. De otro modo se iría al desastre, tal como sucedía en el relato de Block, donde, por culpa de una huelga, los empresarios quebraban, mientras los obreros, que habían sido seducidos por la perversa ensoñación estatalista de los socialistas, perdían su empleo. Ello era la consecuencia lógica e inevitable de haber obviado, tanto patronos como obreros, las doctrinas y prácticas "sanas", las únicas con las que se podía alcanzar una solución para los intereses encontrados. Pou ya había defendido estas mismas ideas sobre una solución armónica del conflicto social en una ponencia presentada al I Congreso Católico de Madrid de 1889, antes de la $R N^{27}$. Y las repetiría dos años después, en 1891, en el prólogo a otro libro que él mismo tradujo, El patrono, del profesor Charles Périn, perteneciente a la escuela católico-liberal de Angers (proclive a los planteamientos del liberalismo económico y reacia al intervencionismo del Estado). Pou, como su amigo Périn, estaba convencido de que, en un mundo en el que lo material debía plegarse al orden moral, el catolicismo era la única garantía de solución a la "cuestión social".

27 Como “excepcional” la calificó Montero, F. (1983), pp. 131-145. 
Otro destacado texto publicado en sus inicios por la RCCS fue el comentario bibliográfico que el integrista J.M. Ortí y Lara escribió sobre la segunda edición, de 1895, del libro de A. Vicent Socialismo y Anarquismo (1893). Lo que aquí interesa no es la valoración hagiográfica que hizo del libro el citado Ortí -influyente figura del Consejo de Redacción e ilustre pensador católico-, sino el concepto de "cuestión social" que explicitó. Podía tomarse en dos sentidos: como falta de creencia en Dios y respeto a la autoridad ${ }^{28}$; o como mala distribución de los bienes derivados de la propiedad y el trabajo, y -por tanto- violación de las leyes de la justicia social. En ambos casos, la "cuestión social" se reducía a un problema moral y religioso: en el primero de forma directa, y en el segundo indirecta (pues la economía no podía nunca desligarse de los aspectos morales). En consecuencia, para su resolución bastaban la limosna y la caridad, sin "reformismos" de ningún tipo.

Finalmente, debe mencionarse al director de la Revista, J.I. Urbina. Su actividad fue frenética tanto como publicista y autor de numerosas colaboraciones, como en labores de trastienda (seleccionado textos para su reproducción, confeccionando reseñas, o redactando notas informativas y anuncios publicitarios). A él se debe, sin duda, la especial cobertura que la Revista dio a los asuntos relacionados con el seguro, el ahorro popular, el crédito o la cooperación, temas recurrentes en su propia pluma y en muchas colaboraciones. En julio de 1896, Urbina reprodujo en la RCCS la respuesta que había dado a la pregunta que le había formulado la revista francesa L'Emancipation, sobre si la reforma moral (cristiana) debía "preceder o seguir a la social" (condiciones de existencia ${ }^{29}$. A Urbina no le cupo la menor duda: la reforma moral debía preceder a la social, de la misma manera que "la formación de un cimiento sólido" precedía "a la construcción de todo el edificio". Y es que "no [podía] haber orden social donde exist[ía] desorden moral" y se anteponía "la cuestión del estómago"30.

Urbina prestó también gran atención al cooperativismo, del que sería gran impulsor junto a otros publicistas, como los economistas católicos gallegos Joaquín Díaz Rábago y Alfredo Brañas, colaboradores de la Revista y su Consejo de Redacción. El primer texto sobre el tema lo publicó Urbina en oc-

\footnotetext{
28 A la sociedad "le falta una sola una cosa, le falta Dios", decía en una carta pastoral el prelado integrista de la diócesis de Cartagena Tomás Bryan y Livermore. La Redacción la calificó de "hermoso documento" y la Revista difundió un fragmento (RCCS, n5, 1895, pp. 74-75).

29 RCCS, nº19, 1896, pp. 139-141.

30 RCCS, n³2, 1897, pp. 169-170.
} 
tubre de $1895^{31}$. Frente al colectivismo - que mataba toda iniciativa- $\mathrm{y}$ al individualismo -que se basaba en el egoísmo e incitaba a la lucha entre capital y trabajo-, el cooperativismo se presentaba como la única solución armónica ${ }^{32}$ : hacía posible la participación de todos en los frutos de la actividad (e incluso en su gestión), favorecía la unión, y facilitaba una mayor equidad. Por otro lado, las cooperativas fomentaban la emulación hacia el trabajo bien hecho, y podían permitir que aquellos individuos que así lo deseasen obtuviesen los bienes necesarios para establecerse por su cuenta, llevando una independencia honrada y logrando un mayor grado de libertad. Es decir, las cooperativas, como solución de compromiso, podían satisfacer tanto a colectivistas como a individualistas, pues mantenían valores de ambas opciones. En este sentido, eran un paso hacia la perfectibilidad de las sociedades humanas. A propósito del II Congreso de la Alianza Cooperativa Internacional, Urbina publicó en 1896 en la $R C C S$-en tres entregas- un extenso artículo sobre "Las rémoras de la cooperación España", que eran la ignorancia, el caciquismo, el abandono y la desunión ${ }^{33}$.

\section{LAS PASTORALES DE JUAN MAURA Y GELABERT}

Los textos más representativos publicados por la RCCS en sus momentos iniciales fueron, sin embargo, las cartas pastorales sobre la "cuestión social" del obispo de Orihuela, Juan Maura y Gelabert, junto a las actas del Congreso Católico de Tarragona (sección 4a). De hecho, los congresos católicos serían considerados por la propia Revista el mejor medio para conocer el estado de la "cuestión social" en España ${ }^{34}$.

Las citadas pastorales y actas muestran una recepción "madura, comprensiva y relativamente generalizada" de la $R N$ por parte de los católicos españoles ${ }^{35}$. Y ello, tanto por el tratamiento dado a los asuntos más controvertidos del catolicismo social europeo (intervencionismo estatal, defensa de la propiedad privada, salario justo y asociacionismo profesional), como por la asimilación de los fundamentos doctrinales de la nueva mentalidad (tales como el

31 RCCS, n¹0, 1895, pp. 165-166.

32 RCCS, n³4, 1897, pp. 217-218.

33 RCCS, nº29, 1896, pp. 211-215; n³0, 1896, pp. 237-240; y n³1, 1896, pp. 262-264.

34 RCCS, $\mathrm{n}^{\circ} 9,1895$, p. 150.

35 Montero, F. (2001), pp. 461-462; Montero, F. (1983), p. 399. 
concepto cristiano del trabajo) o la definición precisa de la "cuestión social" (como antagonismo entre capital y trabajo).

Todas las pastorales sociales de Maura serían íntegramente reproducidas en la $R C C S$ entre 1895 y 1901, con la única excepción de la primera, algo anterior $(1893)^{36}$. Maura fue, con el ovetense Victoriano Guisasola ${ }^{37}$, uno de los intérpretes privilegiados de la $R N$ y un tomista renovado dentro de la jerarquía eclesiástica de la época. Sus pastorales constituyeron una reflexión global y profunda sobre la cuestión social (cuyas causas económico-sociales conocía bien), rechazando cualquier planteamiento reformista que no considerase de forma expresa los valores cristianos.

En su primera carta había señalado que la "cuestión social” sólo se podría resolver conjuntamente desde la moral cristiana y la ciencia económica. Esta, con sus herramientas, ayudaría a diseñar reformas que elevaran las condiciones de vida de la clase obrera ${ }^{38}$. Eso sí, siempre que el enfoque adoptado por la ciencia económica (y por la ciencia en general) no fuera ateo, positivista y puramente utilitarista. Porque esto equivalía a negar a Dios y atacar los fundamentos de la moral, llevando en último término a un laicismo agresivo y un materialismo extremo, de los que nacían -inevitablemente- el conflicto social y doctrinas como el socialismo.

La segunda pastoral de Maura, sobre la concepción cristiana del trabajo, fue la primera del prelado oriolano que publicó la RCCS en 1895, coincidiendo con Permoti $\mathrm{Nos}^{39}$. No contemplaba el trabajo como maldición o castigo impuesto, sino como "función nobilísima que engrandece a la criatura racional y la dignifica", destino natural y fin de la existencia del hombre. Era un factor indispensable de progreso social que, si se entendía en un sentido equivocado, despojándole de su finalidad moral cristiana, se podía transformar en un elemento de destrucción y muerte. De hecho, esto era lo que efectivamente estaba sucediendo, al extenderse concepciones económicas erróneas, absurdas y emanadas del utilitarismo positivista, que habían vendido a complicar y agravar la "cuestión social". Maura desaprobaba la libertad "ilimitada" y "sin trabas", con la misma energía que condenaba sus nocivas secuencias: usura, monopolio, "acaparamiento y otros innumerables abusos" ${ }^{40}$. Por eso, el trabajo

36 Las pastorales han sido estudiadas por Montero, F. (1983), pp. 283-289, Blasco, I. (2013) y Ángel, J.M. (2009).

37 Primado de Toledo de 1914 a 1920.

38 Maura, J. (1993), p. 10.

$39 R C C S, \mathrm{n}^{\circ} 3,1895$, p. 45. La pastoral sobre el trabajo en $R C C S, \mathrm{n}^{\circ} 8,1895$, pp. 127-134.

40 RCCS, nº8, 1895, p. 130. 
-considerado como función social y factor indispensable de progreso- "no [podía] menos de ser prudentemente intervenido y dirigido" por el Estado, que había de "velar por el bien de la sociedad, ampliando o restringiendo la libertad individual conforme a los eternos principios de la moral y las variables exigencias del bien común", pero sin por ello perjudicar "los derechos individuales legítimos y fundados en la justicia y la razón”. En este sentido, Maura insistiría -siguiendo la $R N$ - en que la Iglesia no rechazaba, sino que defendía y amparaba "las libertades legítimas y razonables", aquellas que estaban "en conformidad con los eternos principios de la moral" cristiana ${ }^{41}$. Además, no se oponía radicalmente a la economía política liberal, sino que solicitaba su concurso para solucionar la "cuestión social". Exigía -eso sí- que las políticas económicas se inspirasen en la religión y la moral, considerándolas elemento esencial de todo sistema económico. Frente a la ley de la armonía universal propia de la utopía liberal, planteaba la fe en la Providencia divina, que sabría restablecer el equilibrio de donde nacería un desarrollo verdadero. Es decir, lo que demandaba Maura era una economía política adaptada a los valores cristianos.

Por último, Maura también consideraba el trabajo como fundamento del derecho de propiedad privada y de las desigualdades sociales, tomados como pretexto para el odio por parte de socialistas y anarquistas. A sendos temas dedicaría las pastorales sociales tercera ${ }^{42}$ y cuarta $^{43}$. Las necesidades, aspiraciones y anhelos humanos eran -según Maura- ilimitados, y para cubrirlos el hombre se apoderaba de la materia y la transformaba "produciendo" o "creando" algo; es decir, aplicaba su esfuerzo (facultades físicas e inteligencia) a perfeccionarla y adaptarla, dándole un modo de ser especial. A cambio de dicho esfuerzo, el trabajador -agrícola o fabril- recibía un salario sobre el que tenía pleno derecho; $y$, si era ahorrador, podría incluso acabar comprando una finca que sería reflejo de su salario, y a la que por tanto tendría asimismo pleno derecho.

Los males del socialismo venían precisamente de anular el derecho de propiedad privada, que era natural, inalienable y necesario para el desarrollo de la personalidad humana. Dicha anulación convertía al individuo en siervo pasivo de un Estado omnipotente, dinamitaba la familia (fundamento social e

41 RCCS, no 8,1895 , p. 133.

42 RCCS, $\mathrm{n}^{\circ} 17,1896$, pp. 105-109, y nº18, 1896, pp. 124-128.

43 RCCS, no 28,1897 , pp. 77-82, y nº29, 1897, pp. 102-107. 
institución previa a cualquier autoridad civil), y fomentaba la envidia social; además, acababa con el incentivo a la laboriosidad y la mejora de la propia condición sostenido por el interés personal. A cambio, sólo se generaba apatía e indiferencia, y -por ende- penuria y escasez. Por eso, en la práctica la anulación de la propiedad acababa resultando inviable, al no reconocer las diferencias naturales que existían de facto.

En efecto, las desigualdades (en ingenio, fuerza física o voluntad) eran consustanciales a la naturaleza humana, y daban lugar naturalmente a diferencias sociales de posición y fortuna, tal como ya señalara Santo Tomás. Si se intentaban evitar, haciendo al individuo esclavo de la colectividad y no retribuyéndole de forma diferencial según sus aptitudes, se eliminaría todo estímulo a la iniciativa individual creativa. Además, las desigualdades eran necesarias para la vida en común (que precisaba de facultades y capacidades diversas) y también formaban parte de la belleza y armonía del universo (que descansaba precisamente en la variedad de seres diferentes que constituían la Creación). Sin embargo, era cierto que las desigualdades de posición y fortuna (derivadas a su vez de la natural desigualdad de capacidades) podían dar lugar a abusos desde un individualismo extremo y un egoísmo sin límites, que sólo buscaba la acumulación de riquezas y se desentendía del prójimo. Tales abusos eran condenables sin paliativos.

Por último, Maura hacía una advertencia clave respecto a la propiedad privada: no podía ser un derecho absoluto, para hacer lo que uno quisiera, ni el uso de las cosas poseídas podía ser arbitrario y caprichoso. La propiedad debía tener -y esta era la gran divergencia respecto al orden liberal- un fin social (o sentido comunitario), y había de estar sujeta a la justicia y encauzada al bien común. En este sentido, la caridad cristiana era (frente al humanismo filantrópico) la que garantizaba el freno al egoísmo, la dignificación del pobre y la armonía de intereses, teniendo su fundamento en el concepto cristiano de la vida, que el prelado precisaría en sus pastorales quinta y sexta ${ }^{44}$. Únicamente desde dicho concepto, base de la caridad, se podía hacer frente a la miseria y al dolor. Finalmente, en sus últimas pastorales sociales Maura expondría las legítimas reivindicaciones del obrero y las obligaciones del patrono.

A partir de 1901, Maura también escribiría varias pastorales sobre la democracia cristiana. En ellas trató de aclarar la solución al problema social glosando la encíclica Graves de Communi (1901), en la que el anciano León XIII

44 RCCS, nº32, 1897, pp. 77-82; nº33, 1897, pp. 203-206. 
fijó límites interpretativos al debate abierto dentro del catolicismo social europeo tras la difusión de la $R N$. El programa de la democracia cristiana era social, no político, y muy conservador. Como se verá más adelante, un estudioso tan calificado como Armando Castroviejo, recibiría con indisimulado entusiamo estas nuevas reflexiones de Maura.

\section{LAS ACTAS DEL IV CONGRESO CATÓLICO DE TARRAGONA (1894)}

Del Congreso Católico de Tarragona, la RCCS reprodujo -por un ladovarios discursos: del canónigo Jaime Colell, reivindicando la figura de Jaime Balmes como sociólogo (primera sesión) ${ }^{45}$; del también canónigo Antonio Balcells, sobre la utilidad de los "círculos obreros" (segunda sesión) ${ }^{46}$; del académico Eduardo Sanz y Escartín, sobre la agremiación de los obreros católicos (segunda sesión) ${ }^{47}$; y del magistral Celestino Rivera y Aguilar, sobre las "causas generatrices del socialismo y anarquismo" (cuarta sesión) ${ }^{48}$. Por otro lado, la Revista también transcribió extractos de las memorias de la sección cuarta (puntos I-VI), así como las conclusiones generales.

De los citados discursos, sólo se hará referencia a los dos más significativos, de Colell y Escartín. Colell comenzó su disertación estableciendo un paralelismo entre Balmes y León XIII: en las obras de Balmes estaría ya el germen de lo que luego sería la $R N$. Para el canónigo de Vic, el filósofo español y el pontífice, que habían llegado a conocerse en Malinas en 1845, eran además dos personalidades muy similares (moderados, equilibrados, tenaces) y compartían ideales: religiosos, políticos, morales y -sobre todo- sociales (la necesidad de una decidida actuación de la Iglesia en el terreno social). Pero al margen de su faceta como polemista político, lo más importante de Balmes según Colell- había sido su contribución sociológica: de hecho, le consideraba uno de los fundadores de la escuela sociológica cristiana a nivel europeo.

Balmes había vivido en un difícil momento de transición y profundos cambios socioeconómicos en España, bajo la "amenaza" del socialismo y el liberalismo. Pero había mantenido siempre las mismas posturas, claras y valientes, nunca dogmáticas. nEn concreto, Colell destacó de él tres aspectos

\footnotetext{
45 RCCS, nº, 1895, pp. 151-158. La Revista reprodujo varios textos de Balmes.

46 RCCS, nº10, 1895, pp. 167-173.

47 RCCS, $\mathrm{n}^{\circ} 11,1895$, pp. 199-206; nº12, 1895, pp. 211-217.

48 RCCS, $\mathrm{n}^{\circ} 13,1896$, pp. $11-16 ; \mathrm{n}^{\circ} 14,1896$, pp. $37-44 ; \mathrm{n}^{\circ} 15,1896$, pp. $62-68 ; \mathrm{n}^{\circ} 16,1896$.
} 
que luego serían muy valorados por los católicos sociales. Primero, su reacción en 1835 frente a la desamortización llevada a cabo por los liberales, advirtiendo del peligro de que, del despojo de los bienes eclesiásticos, el pueblo sacase la lección de que también se podría despojar un día a las clases propietarias (pues se habría perdido el respeto por la institución de la propiedad). Segundo, su oposición frente al racionalismo protestante que condenaba al catolicismo en nombre de la civilización y el progreso. Y tercero, su actitud previa a los sucesos revolucionarios de 1848: ya en 1842, Balmes había denunciado el gran comercio monopolizador, el dominio inhumano del materialismo y el maquinismo, y el capitalismo basado en la acumulación de riquezas por parte de una plutocracia sin entrañas, que dejaba una masa obrera miserable y analfabeta a merced de las ideas de revolución social predicadas desde las doctrinas socialistas de la envidia y el odio. Pero, pese a todo ello, Balmes en ningún momento había pretendido un retorno al Antiguo Régimen.

Collell concluía que únicamente el catolicismo -con su llamada a la caridad, el amor al prójimo y el deber social de los ricos hacia los pobres- sería capaz de combatir la amenaza que suponía el creciente atractivo del socialismo. El liberalismo no sólo era incapaz de ello, sino que además formaba parte del problema.

Sanz y Escartín, por su parte, contrastó su propia época (finales del siglo $\mathrm{XIX)} \mathrm{con} \mathrm{el} \mathrm{pasado} \mathrm{feudal} \mathrm{(contraposición} \mathrm{que} \mathrm{fue} \mathrm{una} \mathrm{constante} \mathrm{en} \mathrm{los} \mathrm{textos}$ de los católicos españoles). Los últimos años del siglo XIX, pese a ser un periodo de aumento prodigioso de la actividad económica, estaban presididos por el antagonismo y el odio entre clases junto a otros perniciosos caracteres: individualismo exacerbado, aislamiento, materialismo, acumulación de riqueza en pocas manos, desigualdad, preponderancia del capital, y derechos de propiedad con plenas garantías, pero sin dignidad para los desfavorecidos. Y todo ello, acompañado por valores como la codicia, la soberbia, el engaño o la vanidad.

A este problemático orden socioeconómico liberal, Sanz y Escartín contraponía un idealizado mundo medieval que, pese a haber sido un periodo cargado de dificultades y adversidades, se habría caracterizado -en su opiniónpor armonía social, lealtad, solidaridad, aceptación de la subordinación dentro de una jerarquía connatural a cualquier sociedad organizada, e incluso cierta posibilidad de representación en asambleas municipales. Un mundo presidido por la religión y la moral, que inspiraba la caridad en los poderosos y la resignación en el hombre corriente, además de la dignificación de la familia, la aceptación de los deberes y el respeto a la autoridad. Por otro lado, el gremio, 
institución básica entonces, garantizaba el no abuso en los precios, la confianza en los intercambios y la calidad de los productos.

Escartín entendía que en el capitalismo de finales del siglo XIX faltaba equidad en la distribución de la riqueza social. Si bien era cierto que el Estado podría ocuparse de ello, su acción conllevaba peligros. El ideal era que la propia sociedad civil, a través del asociacionismo, diera respuesta al problema (pues la iniciativa social debía prevalecer siempre sobre la estatal, a la que sólo le correspondía una función subsidiaria). Pero si las asociaciones se mantenían alejadas en sus fines de la moral y la religión, sin ir más allá de lo meramente material, su actuación tampoco serviría de nada. La reforma moral, pues, había de preceder a la social. De no ser así, persistiría el conflicto de clases y el auge de las doctrinas socialista y anarquista. Sólo el catolicismo social podría presidir la necesaria reacción asociativa en forma de agremiación: por ejemplo, asociaciones profesionales mixtas bajo el ideal cooperativo, humanitario y cristiano.

Las memorias que se presentaron a la Sección Cuarta del Congreso de Tarragona, agrupadas en seis bloques, fueron muchas, y por tanto también fueron abundantes los extractos reproducidos en la RCCS. Aquí sólo se hará breve alusión a aquellas más relevantes.

Tal como señaló en su ponencia el integrista Félix Sardá y Salvany, la noción del trabajo como castigo divino impuesto por Dios estaba muy extendida. Pero para los católicos, gracias a la "regeneración del hombre por Cristo", dicho castigo había sido "trocado en nobilísima virtud" cibido, Sardá proponía impulsar asociaciones dirigidas por los prelados, a ser posible mixtas (tipo círculos católicos), donde se difundieran "conocimientos útiles" y se realizaran "obras de piedad" adaptadas al "espíritu de la clase obrera". Y ello sin menoscabo de "las necesidades materiales" que habían constituido el banderín de enganche de las "sectas anticristianas". En el pensamiento integrista de Sardá, el pobre siempre era considerado un "menor" dentro de la gran familia cristiana, a cuyo cargo estaban tutores "a los que la Divina Providencia" había constituido "en elementos directores del orden social" por su autoridad, saber o riqueza.

La reflexión doctrinal más fundamentada sobre el concepto de "salario justo” fue la de Ángel Sánchez-Rubio Ibáñez, marqués de Valle Ameno, quien

49 RCCS, nº12, 1895, pp. 219-220. 
fue catedrático de Economía Política y Hacienda Pública en Zaragoza y asiduo participante en los congresos católicos ${ }^{50}$. Para él, el salario no podía ser simplemente el resultado de las leyes de la oferta y la demanda, porque la idea de libertad de contratación era más aparente que real: el obrero necesitaba trabajar, tanto para proveerse su sustento y el de su familia, como por una mera cuestión de deber moral. El salario del obrero debía ser en general suficiente para sostener una familia media de cuatro miembros (pues los casos de obreros solteros o viudos eran absolutamente excepcionales). De cualquier forma, la economía debía estar subordinada a la moral y a la idea de justicia: al obrero le correspondía en derecho un salario por contribuir a la producción, igual que contribuía el empresario con su dirección o el sabio con su invención. Además, su derecho a la participación en el producto debía compensar plenamente los gastos realizados por el trabajador para llevar a cabo su labor, al igual que había que destinar una parte del producto obtenido a renovar el capital o compensar su depreciación. Cabía incluso plantear que el trabajador participase también en los beneficios resultantes tras deducir gastos de ingresos, aunque no era fácil determinar dicha participación en industrias complejas.

Por otra parte, según Valle Ameno, el patrono tenía la obligación de poner los medios para que el trabajo se realizase en condiciones de salubridad y para que las mujeres y los niños no hiciesen labores que pudieran perjudicarles. Todo ello suponía un coste módico y perfectamente asumible para el empresario. En cuanto al Estado, había de cumplir una misión tutelar subsidiaria, de forma que a través de la legislación civil sobre contratación garantizase la justicia en la retribución del obrero, con tribunales que dirimieran los posibles conflictos. Y respecto a las autoridades municipales, podían aportar criterios para establecer cuál debía ser el jornal medio según los niveles locales de vida, amparando asimismo al obrero como parte débil en la contratación. En definitiva, la resolución del problema de los salarios justos se facilitaría si se generalizaran las corporaciones gremiales, si la familia fuera considerada una institución central, y si la Iglesia tuviera mayor presencia social para transmitir las ideas de equidad de San Alberto Magno o Santo Tomás de Aquino.

50 RCCS, $\mathrm{n}^{\circ} 18,1896$, pp. 183-184. Sobre los salarios habían hablado también el canónigo tarraconense Rafael Tous y Ferrá (RCCS, nº19, 1896, pp. 144-146) y el abogado y publicista conservador Joaquín Borrás y de March (nº16, 1896, pp. 89-91). 


\section{RAFAEL RODRÍGUEZ DE CEPEDA, ANTONIO TORRENTS Y ARMANDO CASTROVIEJO}

Quien mejor concretó la acción de los "poderes públicos" en la llamada "cuestión social" fue Rafael Rodríguez de Cepeda, un intelectual vinculado al Padre Vicent que también participó como ponente en la Sección Cuarta del Congreso de Tarragona. Miembro del Consejo de Redacción de la Revista, reputado profesor de Derecho Natural próximo a la neoescolástica, y Doctor Honoris Causa por la Universidad de Lovaina ${ }^{51}$, Rodríguez de Cepeda fue un personaje muy conocido por ser autor de un exitoso manual, por su habitual presencia en los congresos católicos nacionales e internacionales, y por haber publicado numerosos trabajos relativos a la "cuestión social". Por ejemplo, respecto a la reglamentación de las condiciones de trabajo, la función y límites del derecho de propiedad, o la protección legal de los trabajadores. Sobre esta última cuestión, como representante español en el I Congreso Internacional de Protección Obrera de Zúrich (1897), presentó una memoria cuyo contenido ampliaría posteriormente en distintas conferencias. Cuatro de ellas, dictadas en Valencia a principios de 1903, serían reproducidas íntegramente por la Revista ${ }^{52}$.

Para Rodríguez Cepeda, la cuestión obrera había surgido con el desarrollo de la "gran industria" moderna, y consistía "en un desequilibrio [...] en las relaciones del trabajo", que situaba a ingentes masas obreras en una situación precaria: unas veces por la insuficiencia de los salarios, y otras por la inseguridad del porvenir (accidentes, enfermedades, vejez o paro). Es decir, la cuestión obrera derivaba, de un lado, del surgimiento de la moderna industria, y de otro, de los abusos de los patronos que, olvidándose de la ley moral, se dejaban arrastrar por el espíritu del egoísmo ${ }^{53}$. Ante este panorama de frecuentes abusos de unos y sufrimiento de otros, al poder público no le quedaba más opción -según el jurista valenciano- que intervenir dentro de los límites prudentes señalados por la $R N$ : dictando leyes en defensa de las clases obreras, y garantizando condiciones de trabajo compatibles con la integridad y el desarrollo de su personalidad física y moral. Exactamente en eso consistía la

51 Para Peset, M. y Blasco, I. (1992), p. 397, Rodríguez de Cepeda es buen ejemplo de la pervivencia de las viejas ideas que dividían España en dos bloques de pensamiento a finales del siglo XIX. Llano Torres, A. (1994), pp. 469 y 475, ha destacado la influencia que ejercieron en él Toniolo, Taine y Le Play, entre otros.

52 RCCS, $\mathrm{n}^{\circ} 102,1903$, pp. $321-332 ; \mathrm{n}^{\circ} 104,1903$, pp. 448-459; n ${ }^{\circ} 105,1903$, pp. $518-531 ; \mathrm{n}^{\circ} 106,1903$, pp. $577-590$.

53 RCCS, nº102, 1903, pp. 329. 
protección legal de los trabajadores, no en su emancipación. En tal sentido, y sólo en él, la intervención protectora del Estado frente a la "cuestión social" sería justa y necesaria, entendida siempre desde el respeto a la libertad y al principio de subsidiariedad que prescribía la $R N$.

Coincidiendo con el primer año de vida de la RCCS, el catedrático de Economía Política de la Escuela Superior de Comercio de Barcelona, Antonio Torrents y Monner, publicó su Tratado de Economía Política (1896). Fue un manual que mereció los elogios del secretario de Estado de León XIII, cardenal M. Rampolla, por la sencillez y claridad con que explicaba la doctrina pontificia sobre los obreros ${ }^{54}$. Varios años más tarde, en 1903, publicaría en la Revista un sucinto texto doctrinal titulado "La sociedad humana"

Torrents pensaba que el hombre era un ser sociable por naturaleza, dotado de libre albedrío, inteligente, responsable de sus actos y perfectible. En su opinión, la organización social se sustentaba sobre cuatro bases: la religión (moral cristiana), la familia (principal fundamento social), la autoridad (que dirigía, establecía normas y daba seguridad), y la propiedad privada (indispensable para el desarrollo). Esta última se justificaba a su vez desde tres puntos de vista: ético (derecho a los frutos del propio esfuerzo), económico (incentivo a la mejora y la actividad), y político (base de la libertad individual para disponer de bienes, tomar opciones y desarrollar las propias facultades $)^{56}$. De ahí se infería que la "cuestión social" no era tan solo un asunto económico, ni tenía su único origen en la lucha entre capital y trabajo; tampoco se resolvería solamente con una más equitativa distribución de la riqueza. La agitación social del momento obedecía a causas morales tanto o más que a causas materiales. Por eso, Torrents acababa su reflexión animando a "predicar las sanas doctrinas [de la $R N$ ], que [conducirían] al afianzamiento de la armonía y el bienestar social".

Finalmente, el economista Armando Castroviejo es el último autor al que se hará referencia en este apretado relato sobre la recepción de la $R N$ en la $R C C S$ durante sus primeros años. Con motivo del $1^{\circ}$ de mayo de 1901 , publicó un texto demostrativo de la nueva mentalidad católico-social que él mismo representaba. Consistía básicamente en la "asunción cristiana de las reivindicaciones obreras justas" ${ }^{57}$. A diferencia de otros autores, Castroviejo

\footnotetext{
54 RCCS, nº5, 1896, p. 120.

55 RCCS, nº9, 1903, pp. 137-144.

56 RCCS, nº100, 1903, p. 206.

57 Montero, F. (1983), pp. 358-359. RCCS, nº5, 1900, pp. 264-267.
} 
no sólo no las reprobaba, sino que apelaba a todos los católicos a que afrontaran la situación con realismo, y a que imitaran a sus enemigos, los socialistas $\mathrm{y}$ anarquistas, en la labor de propaganda.

En 1899, siendo aún profesor auxiliar en la Universidad de Granada, entró a formar parte del Consejo de Redacción. Desde ese mismo año -como ya se ha indicado- se hizo cargo de la importante sección bibliográfica, que se convertiría en un vehículo único de difusión ideológica del catolicismo social hasta el término de la Revista en 1930. Pero también aportó varios textos, exclusivos unos y reproducidos otros, como el titulado "El programa económico cristiano" de 1904 (cuando ya era Catedrático de Economía Política en Sevilla). En él, sobre la base de la "teología católica explicada por Santo Tomás" 58 , expuso de forma breve y brillante su visión de determinados aspectos de la "cuestión social" 59 . Para Castroviejo, en la línea de Maura y Valle Ameno, el trabajo era una obligación moral, además de fuente de toda riqueza y base de la solidaridad y la cooperación para la vida; la propiedad, por su parte, como derecho anclado en la misma naturaleza humana, era un estímulo para la producción y un incentivo básico para el trabajo digno y el ejercicio de la caridad. $¿$ Qué faltaba entonces -se preguntaba- para que las artes prosperasen, los oficios se ennobleciesen, los pobres se tornasen ricos, y la felicidad se complaciera "en sentar sus reales entre los hombres?" plementarias: que la moral cristiana imperase en la economía política, que la ley amparase al desvalido, y que el poder público impidiese legítimamente, cuando fuera necesario, los desmanes de los poderosos ("legítimas injerencias" del Estado).

Castroviejo defendió, por tanto, la necesidad de una restauración cristiana de la vida económica en la que prevaleciera la ley moral, cuyo arquetipo -como Sanz y Escartín- creyó encontrar en el idealizado mundo medieval: los gremios hacían que el trabajo fuera socialmente valorado; la posesión de los instrumentos de producción garantizaba los frutos del propio esfuerzo, sin temor a crisis derivadas del juego de la oferta y la demanda; y el trabajador disponía de lo suficiente para cubrir sus necesidades y mantener decorosamente a su familia, contando además con suficiente tiempo de ocio.

58 RCCS, n ${ }^{\circ} 112,1904$, p. 229.

59 RCCS, $\mathrm{n}^{\circ} 112,1904$, pp. 226-232; $\mathrm{n}^{\circ} 113,1904$, pp. 273-280.

60 RCCS, nº113, 1904, p. 274. 
Este idílico orden medieval (¿creía en él realmente Castroviejo?) se había roto con la industrialización. El triunfo del capitalismo había traído el dominio absoluto del mercado impersonal, el despojo de los bienes comunales y de la Iglesia, la pérdida de la consideración social del trabajo y del sentido ético de la propiedad, el renacer de la usura, el establecimiento de la "gran industria", y las crisis recurrentes. Todo ello había dado lugar a masas obreras en malas condiciones de vida, dislocando la familia, la salud y la vida infantil, y llevando a la miseria y al hambre a grandes colectivos. Además, las asociaciones de trabajadores habían sido inicialmente prohibidas, en clara asimetría frente a las posibilidades patronales. De este modo, se había acabado creando una sociedad apóstata y materialista, a la deriva y sin sentido.

Frente a ella, Castroviejo proponía devolver la moral cristiana a la esfera económica mediante reformas concretas: por ejemplo, modificar el contrato industrial buscando la igualdad trabajo-capital, permitir la participación de los obreros en la elaboración de los reglamentos fabriles, establecer consejos mixtos de patronos y trabajadores, crear gremios o sindicatos católicos, favorecer la pequeña industria, promover instituciones de previsión y socorro mutuo, promulgar legislación social que amparase a los oprimidos, o impulsar el cooperativismo. Parte de estas actuaciones ya se estaban llevando a cabo en varios países y -aunque con cierto retraso- también en España, como reconocía el propio Castroviejo.

En cualquier caso, insistía en que la democracia cristiana era la única garantía de regeneración, tanto frente al socialismo estatista que acaba con la individualidad, como frente al feroz capitalismo liberal sin cortapisas. Como se señalaría repetidas veces en la propia Revista, y siguiendo estrictamente la línea marcada en la Graves de Communi, la democracia cristiana representaba todo lo contrario: era indiferente a las formas de gobierno, y no provocaba enfrentamientos entre los componentes de la sociedad ni buscaba igualar las riquezas. Al revés, admitía y defendía la propiedad particular y la jerarquía de clases como baluarte de la libertad y causa necesaria del progreso. Tampoco se apoyaba en la fuerza, sino en la justicia y la caridad ${ }^{61}$.

Se trataba de lo que el obispo Maura, reafirmando a Castroviejo en sus convicciones, había denominado "vía intermedia" entre dos "extremos vicio-

61 RCCS, n71, 1900, pp. 641-648.

62 RCCS, nº6, 1902; nº7, 1903, pp. 1-7. 
sos": el "individualismo egoísta, violento y opresor", que no reconocía "otra ley que la del más fuerte ni otra moral que la moral utilitaria", y el "socialismo nivelador", que sacrificaba "al individuo en aras de la colectividad" y negaba la sociedad de clases y la propiedad privada. Los elementos constitutivos de esta tercera vía eran la libertad, la igualdad y la fraternidad ${ }^{62}$.

\section{CONCLUSIÓN}

Eduardo Dato, en una de sus conferencias en la Academia de Jurisprudencia (1912), se refirió expresamente a Castroviejo como uno de los más documentados sociólogos españoles ${ }^{63}$. Dato había sido uno de los principales responsables del gran vuelco hacia el intervencionismo tutelar y subsidiario del Estado en las cuestiones sociales, iniciado con el cambio siglo. Para llevarlo a cabo, el político gallego había contado con la colaboración decidida de reformadores sociales krauso-institucionistas y con la ayuda inestimable de católicos sociales, muchos ligados a la Revista. Además, en 1910, en su discurso de ingreso en la Real Academia de Ciencias Morales y Políticas, había defendido la compatibilidad y complementariedad necesarias entre justicia social y caridad cristiana.

Esta era una cuestión polémica, a la que el cardenal de Toledo -Guisasola- dedicó la pastoral "Justicia y Caridad en la organización cristiana del trabajo" (1916), reproducida por la Revista ${ }^{64}$. Castroviejo acompañó la noticia con una breve reseña laudatoria. A su entender, la pastoral reflejaba el hondo cambio operado en la conciencia católico-social española desde hacía veinte años, hasta "colocarse en las avanzadas de la acción social católica"; además, contenía criterios orientativos muy pertinentes sobre cómo había de actuar "la sindicación obrera", criticando el "patronalismo tutelar todavía preconizado por algunos" ${ }^{65}$.

Si bien el cardenal y Castroviejo pecaban de demasiado optimismo (pues en la Revista aún abundaban los testimonios de la mentalidad benéfico-asistencial $\left.{ }^{66}\right)$, no dejaba de ser cierto que para entonces se habían realizado gran-

63 RCCS, n²22, 1913, pp. 452-453.

64 RCCS, n²59, 1916, pp. 18-25; n²60, pp. 77-85; n²61, pp. 148-158; n²62; n²63, pp. 214-223; $\mathrm{n}^{\circ} 263$, pp. 273-283.

65 RCCS, nº255, 1916, pp. 210-211.

66 Claro ejemplo de ello es la interpretación, completamente diferente, que realizó de la pastoral el integrista Sánchez Cuesta (RCCS, nº255, 1916, pp. 220-222). 
des avances en el convencimiento de lo insuficiente de las soluciones tradicionalmente propuestas: el libre mercado puro al que apelaba el liberalismo radical, la beneficencia propugnada por la Iglesia, o el ahorro y el auxilio mutuo practicados por los obreros. Sin descalificar la aportación cristiana de la caridad y mirando con reticencia al liberalismo político (por muy confesional que se declarase), Castroviejo y los reformadores social-católicos abogaban por el salario familiar justo frente a la mera regulación del mercado de trabajo, defendían el derecho al asociacionismo obrero, y -con matices- aprobaban cierto grado de intervencionismo estatal, a fin de proteger las condiciones laborales y vitales del trabajador.

No obstante, todo lo anterior no debe inducirnos a pasar por alto el profundo conservadurismo de sus textos, apoyados siempre de forma rigorista en un magisterio eclesial episcopal marcadamente conservador y garante del orden social ${ }^{67}$; tampoco debe hacernos olvidar la escasa permeabilidad que mostraron en lo que respecta a los avances científicos, sociológicos y económicos. Es decir, aunque en la RCCS convivieron desde el principio visiones "integristas" con otras más "avanzadas" -como la democracia cristiana-, la interpretación de la $R N$ que en general hicieron sus colaboradores fue bastante tradicional y conservadora ${ }^{68}$.

Finalmente, conviene también recordar que buena parte del catolicismo social -y la RCCS no fue una excepción ${ }^{69}$ - aceptó con agrado la dictadura de Primo de Rivera, instaurada en 1923 y apoyada por la oligarquía conservadora (a cuyos miembros correspondió con beneficios, poder o reconocimiento social $)^{70}$. La razón fue que el nuevo régimen autoritario con tintes corporativistas parecía alejar el peligro secularizador representado por el liberalismo, ofreciendo a cambio la oportunidad de hacer realidad el proyecto recristianizador de la sociedad. Pero esto ya es otra historia.

67 Esta idea general no supone negar que hubiera algún obispo audaz en lo social.

68 "La definición oficial pontificia, en Graves de Communi (1901), limitando el significado del concepto «democracia cristiana» al de mera acción social en favor del pueblo, rechazaba cualquier otra interpretación liberal-democrática, que algunos propagandistas del catolicismo social defendían a comienzos del siglo" (Montero, F., 2007, p. 107).

69 Dos meses después del golpe de estado, Sánchez Cuesta agradecía al Directorio haber restablecido la "paz social” (RCCS, n³47, 1923, pp. 268-270). Suárez Urbina, por su parte, dedicó al dictador un largo poema repleto de ditirambos (RCCS, n⿳0370, 1925, pp. 211-12).

70 Perfecto, M.A. (1984), p. 137. 


\section{BIBLIOGRAFÍA}

Andrés-Gallego, José (1984), Pensamiento y acción social de la Iglesia en España, Espasa-Calpe, Madrid.

Ángel, José Manuel (2009), La cuestión social y la idea de democracia cristiana en el pensamiento del obispo Maura, Tesis Doctoral, Universidad de Murcia.

Blasco, Inmaculada (2013), "Catolicismo Social y Reforma Social en España”, en Cabrera, Miguel Ángel (ed.), La ciudadanía social en España, Universidad de Cantabria, Santander, pp. 61 -90.

Campo, Carlos (2011), "Eduardo Sanz y Escartín: el reformismo de un católico conservador", Miscelánea de Comillas, n 69, pp. 177-205.

Capellán, Gonzalo (2005), "Cambio conceptual y cambio histórico. Del pauperismo a la «cuestión social»”, Historia Contemporánea, n 29, pp. 539-590

Castroviejo, Armando (1900), La democracia cristiana, Imprenta Revista Católica, Madrid.

Faes, Enrique (2003), "Poder político y poder económico en la Restauración. Una interpretación divina (la singular formulación del segundo Marqués de Comillas)”, Historia y Política, nº 9, pp. 9-39.

Flores Manzano, Fernando (2012), "Acción Católica y asociacionismo agrario en la diócesis de Plasencia”, Revista de estudios extremeños, vol. 68, n 2, pp. 771-816.

González Cuevas, Pedro Carlos (2001), "Las tradiciones ideológicas de la extrema Derecha española”, Hispania, n 207, pp. 99-142.

González Cuevas, Pedro Carlos, y Montero, Feliciano (2001), "Los conservadores españoles", en Morales, Antonio (coord.), Las claves de la España del siglo XX, Tomo IV, Sociedad Estatal Nuevo Milenio, Madrid, pp. 39-62.

Hernández Cano, Eduardo (2017), "Notas sobre la colección literaria en la edición católica en España (1842-1939)”, en Rivalan, Christine y Cicolí, Miriam (eds.), La Colección, Universidad de los Andes, Bogotá, pp. 175-202.

Hibbs-Lissorgues, Solange (1995), Iglesia, prensa y sociedad en España (1868-1904), Instituto "Juan Gil-Albert", Alicante.

Llano Torres, Ana (1994), "Rafael Rodríguez de Cepeda y Marqués: Un filósofo del Derecho español del siglo XIX", Anuario de Filosofía del Derecho, XL, pp. 467-496. 
Martín Rodríguez, Manuel (2020), "La escuela católica de economía en España: Profesores y libros de texto (1875-1936)", Iberian fournal of History of Economic Thought, vol. 7, n 2, pp. 101-122.

Maura, Juan (2011), Carta Pastoral del 3 de diciembre de 1893, Biblioteca Saavedra y Fajardo de Pensamiento Político Hispánico.

Montáchez, Roberto C. (2000), "León Leal Ramos (1881-1959). Una vida entregada al apostolado", Coloquios Históricos de Extremadura, pp. 1-29. [Disponible en https://chdetrujillo.com/leon-leal-ramos-1881-1959-una-vidaentregada-al-apostolado-social/?pdf=8063]

Montero, Feliciano (1983), El primer catolicismo social y la Rerum Novarum en España (1889-1902), CSIC, Madrid.

Montero, Feliciano (1984), "La relación Iglesia-Sociedad en la España de la segunda mitad del siglo XIX", Revista de Historia Contemporánea, $\mathrm{n}^{\circ} 3$, pp. 87-98.

Montero, Feliciano (2001), "La crítica católica de la economía clásica y el primer catolicismo social”, en Fuentes Quintana, Enrique (dir.), Economía y economistas españoles, vol. 5, Galaxia Gutenberg, Barcelona, pp. 451-493.

Montero, Feliciano (2007), "La derecha y el catolicismo español: del integrismo al socialcristianismo", Historia y Política, n 18, pp. 101-128.

Orella, José Luis (2012), El origen del primer catolicismo social español, Tesis Doctoral, Universidad Complutense de Madrid, Departamento de Educación.

Perfecto, Miguel Ángel (1984), "Corporativismo y catolicismo social en la Dictadura de Primo de Rivera”, Studia Histórica. Historia contemporánea, $\mathrm{n}^{\circ}$ 2, pp. 123-147.

Périn, Carlos (1891), El patrono. Sus funciones, deberes y responsabilidades, Subirán, Barcelona.

Peset, Mariano, y Blasco, Yolanda (2008), "Humanismo, soberanía y religión. Rafael Rodríguez de Cepeda (1850-1918), un catedrático de Valencia conservador", en Velasco, Ambrosio (coord.), Significación política y cultural del bumanismo iberoamericano en la época colonial, Plaza y Valdes, Mexico, pp. 397430.

Revista Católica de Cuestiones Sociales (1895-1930), Madrid. 
